\title{
Polissemia do verbo "partir" sob a perspectiva da teoria sentido-texto
}

\author{
Lílian Thais de Jesus ${ }^{\mathrm{i}}$
}

\begin{abstract}
RESUMO
A polissemia e a homonímia são fenômenos que, apesar de sua importância e abundância nas línguas naturais, não são tratados, nos dicionários gerais de língua portuguesa, a partir de metodologias linguísticas definidas. Este trabalho objetiva oferecer uma possibilidade de tratamento do verbo partir, através das Funções Lexicais do Modelo Sentido-Texto, a fim de se poder evidenciar acepções relacionadas do verbo, portanto polissêmicas, e acepções não relacionadas, logo homônimas. Como método de análise formalizou-se, justamente, acepções do verbo partir em Funções Lexicais do Modelo Sentido-Texto. O resultado da aplicação das funções ao verbo evidenciou ser possível considerar tal verbo não apenas como um verbo polissêmico, mas considerar a possibilidade de duas unidades lexicais, dois verbos homônimos que possuem, por sua vez, dentro de si sua polissemia.
\end{abstract}

Palavras-chave: Teoria Sentido-Texto; Homonímia; Polissemia; Verbos polissêmicos; Verbo partir.

\begin{abstract}
Polysemy and homonymy are phenomena which, despite their importance and abundance in natural languages, in general dictionaries, there is not an established defined linguistic methodology for their treatment. This paper aims to offer a possibility of treatment of the verb "partir" (in English: leave, depart, split), through the Lexical Functions of the Meaning-Text Model, in order to enable to evidence related meanings of the verb "partir", thus polysemic, and unrelated meanings, therefore, homonymous. As method of analysis, the meanings of the verb "partir" was formalized in Lexical Functions. The result of the application of Lexical Functions to the verb "partir" evidenced the possibility of being able to consider such verb as not only a polysemic verb, but also to consider the possibility of two lexical units, two homonymous verbs which have, in turn, its own polysemy.
\end{abstract}

Keywords: Meaning-Text Theory; Homonymy; Polysemy; Polysemic verbs; Verb partir.

\footnotetext{
${ }^{i}$ Doutoranda na área de Lexicografia, Terminologia e Tradução - Relações Textuais, pela Universidade Federal do Rio Grande do Sul (UFRGS); mestra na área de Gramática e Significação pela mesma instituição. Graduada em Ciências da Linguagem pela Faculdade de Letras da Universidade do PortoPortugal (FLUP); e graduada em Letras-Português pela Universidade do Vale do Rio dos Sinos (UNISINOS).

ORCID: https://orcid.org/0000-0002-8896-3690 | lilian-thais@outlook.com
} 


\section{INTRODUÇÃO}

Nos estudos atuais em lexicologia e lexicografia, fenômenos que têm causado grande discussão são a polissemia e a homonímia.

Tratar um item lexical como polissêmico (e definir todos os seus diferentes significados como pertencentes a esse mesmo item lexical apenas) ou definir como homônimas palavras que apenas possuem suas formas ortográficas/fonológicas iguais (ou seja, não haveria apenas um item lexical, mas dois ou mais) não é tarefa fácil.

Esse quadro acontece porque não parece haver metodologias bem estabelecidas para o tratamento destes fenômenos em lexicografia prática. Como apontado por Mel'čuk (1995, p. 59), trata-se, assim, de um problema delicado e árduo, porque há muitas consequências emergidas a partir de uma tomada de posição (como, por exemplo, o fato de que entender uma unidade lexical como polissêmica faz com que ela receba apenas uma entrada no dicionário, já considerá-la homonímica implica a sua separação em mais de uma entrada).

Perini (2004, p. 250) aponta para o fato de que a polissemia e a homonímia são "noções básicas que, não obstante sua importância, nunca foram convenientemente definidas.”. O gramático linguista ilustra que, tradicionalmente, as palavras são classificadas em homônimas e polissêmicas de acordo com critérios heterogêneos. Nesses diferentes parâmetros, pode-se considerar a existência de homonímia por critérios gramaticais ou quando há uma diferença de significado bastante nítida, por exemplo. No entanto, ainda conforme o mesmo autor, diferenciar polissemia e homonímia apenas por critérios semânticos é um "problema".

Assim como observado por Perini (2004), diferentes são as abordagens ao classificar unidades lexicais como polissêmicas ou homonímicas e, inclusive, há problemas nelas. Deste modo, faz-se importante refletir sobre meios linguísticos e criteriosos de se distinguir um item lexical como polissêmico/homonímico.

Tendo em conta esse quadro, o presente trabalho pretende refletir sobre um verbo apresentado como polissêmico no Pequeno Dicionário Houaiss da Língua Portuguesa, neste caso, o verbo partir, procurando oferecer um tratamento a partir da ferramenta de análise dos itens lexicais da Teoria Sentido-Texto, de Mel'čuk (1995), as Funções Lexicais. Essa metodologia é adotada como uma maneira para se confirmar se 
há, de fato, polissemia neste item lexical ou se o mesmo poderia ser dividido em pelo menos dois itens homônimos.

\section{A TEORIA SENTIDO-TEXTO}

A Teoria Sentido-Texto (TST) - teoria criadora das Funções Lexicais, a ferramenta escolhida para a análise metodológica deste trabalho - é a fundamentação teórica para a construção do Modelo Sentido-Texto, que visa a descrição sistemática e formal das línguas naturais. Segundo Milićević (2006), a Teoria Sentido-Texto agrega considerável valor à semântica e considera as línguas naturais como ferramentas para se expressar "sentido". Percebe-se, desse modo, a concepção de língua a partir do ponto de vista do falante que deseja expressar conteúdo e constrói um conjunto de paráfrases possíveis para fazê-lo, escolhendo aquela que melhor se adequa ao seu momento de interlocução. A linguagem é considerada como a correspondência existente entre um número infinito de textos e um número infinito de significados.

Outras particularidades da TST, como se pode observar através da caracterização da teoria realizada por Milićević (2006), são: (1) a ênfase na síntese, ou seja, na emissão linguística realizada pelo falante em detrimento da análise, isto é, a decodificação da mensagem, realizada pelo receptor na paráfrase e no léxico; (2) a consideração das relações lexicais, ao invés das classes, como o grande fator de organização de uma língua; e (3) o uso extensivo do conceito de dependência linguística como primazia frente ao conceito de constituência. Nesse último conceito, há a ideia de um elemento que governa outro, em uma união sintática, ao invés da ideia de que tais elementos apenas "pertencem juntos".

Na abordagem Sentido-Texto, a Teoria Sentido-Texto (TST) tem por objeto a língua considerada como um sistema de regras extremamente complexo, que é codificado no cérebro do falante. Mais especificamente, para Mel’čuk (1997), a língua é um mecanismo de regras que permite ao locutor realizar duas ações: falar, ou seja, ser capaz de fazer uma ligação entre um sentido que se quer expressar e todos os textos capazes de veicular esse sentido, escolhendo aquele que melhor lhe convém; também permite compreender a fala, isto é, realizar a correspondência entre um texto e todos os 
sentidos que podem ser expressos por esse texto, selecionando aquele que melhor se adapta ao ato de fala em que estiver.

Concebendo a língua como um sistema de regras, o linguista Igor Mel’čuk (juntamente com seus colegas) pretendeu construir, para uma língua estudada, um sistema de regras como um programa informático, que definisse essa correspondência entre os sentidos e os textos estabelecidos pelos falantes (MEL'ČUK, 1997, p. 1), daí o surgimento das Funções Lexicais, formalismos que serão mais profundamente definidos na seção 2.2 deste trabalho.

A Teoria Sentido-Texto (TST) apresenta três postulados como base. O primeiro postulado, já anteriormente mencionado, se configura por seu objeto de estudo, a língua natural, sendo concebida como a correspondência entre o sentido que se quer exprimir, e os textos capazes de fazê-lo.

Como segundo postulado, a TST concebe o Modelo Sentido-Texto (MST) como uma ferramenta útil na descrição das línguas. Para Mel’čuk (1997, p. 5), há uma utilização prática do MST no ensinamento de línguas e no tratamento automático (como traduções automáticas) de textos. O modelo pretende reproduzir, da melhor maneira, a correspondência entre o sentido que o locutor quer/precisa expressar e os textos capazes de exprimi-lo.

Por fim, a TST tem como terceiro postulado a ideia de que são, a palavra e a frase, as unidades básicas para descrição linguística. Para a TST, importa a frase e a palavra, mais precisamente a forma de palavra, como as unidades máxima e mínima, respectivamente, da fala, ou seja, as unidades autônomas universais (MEL'ČUK, 1997, p. 6).

O Modelo Sentido-Texto surgiu na década de 60, em Moscou, criado por Alexander Zholkovsky, Jurij Apresjan e Igor Mel’čuk, entre outros colegas.

O que o modelo pretende é ser um sistema de expressões simbólicas, capaz de representar o funcionamento da língua (MEL' $\breve{C} U K, 1997$, p. 3). Despendendo grande atenção aos modelos funcionais, Mel'čuk (1997) afirma ser, o seu modelo, um método funcional, isto é, um modelo em que o pesquisador analisa o seu objeto de estudo no seu funcionamento efetivo. No caso das ciências da linguagem, essa se trata de uma informação imensamente relevante, uma vez que a Teoria Sentido-Texto ou o Modelo Sentido-Texto não pretendem analisar ou refletir sobre a língua em um estado que seja 
separado de seu uso pelos falantes. Não há a pressuposição de um falante ideal (e de um receptor ideal novamente não é caso, também pelo fato de o modelo não realizar a análise da língua do ponto de vista receptivo), mas há a recolha de textos reais, em diferentes contextos de uso, pelo Observatório de Linguística Sentido-Texto (OLST). É, ainda, um modelo funcional global da língua, o qual possui, subjacente a sua formação, a Teoria Sentido-Texto.

\section{$1.1 \mathrm{O}$ fenômeno da polissemia sob a ótica da Teoria Sentido-Texto}

Ao refletir sobre como as funções lexicais podem oferecer um meio de modelização das relações lexicais existentes nas línguas, Polguère (2002) afirma que há casos em que os mesmos significantes são utilizados muitas vezes em associação a mais do que apenas uma lexia ${ }^{1}$. Como aponta Polguère (2002, p. 39, tradução nossa), "Elas servem para exprimir os sentidos lexicais ligados de maneira metafórica, metonímica, etc.".

Um importante comentário, realizado por Polguère (2002, p. 39, grifo do autor, tradução nossa), é o de que há, nesse vocábulo possuidor de um conjunto de lexias, uma intersecção de sentido que é relevante: "Um VOCÁBULO é um conjunto de lexias associadas aos mesmos significantes e em que os sentidos apresentam uma intersecção não trivial.”. Pode-se observar, através da ideia de Polguère (2002), que se trata de polissemia o fato de um mesmo vocábulo se desdobrar em muitas lexias (unidades lexicais), havendo entre elas uma linha de significado que se segue. Para exemplificar tal fato, o linguista aponta a descrição do vocábulo "porc", no dicionário Nouveau Petit Robert:

\footnotetext{
Nos dicionários, nos trabalhos de pesquisa em lexicologia e lexicografia, etc., é costume numerar as lexias de um mesmo vocábulo. Por exemplo, o Nouveau Petit Robert descreve o vocábulo francês PORC sendo constituído por quatro lexias: PORC1 (animal doméstico...), PORC2 (indivíduo sujo...), PORC3 (carne de porco1...) e PORC4 (pele de porco1...). (POLGUÈRE, 2002, p. 40, grifo do autor, tradução nossa)
}

Como aponta Polguère (2002), as diferentes lexias de um mesmo vocábulo formam, então, o que se costuma conhecer na lexicografia como o conjunto de acepções desse vocábulo. Já para o autor, a polissemia ocorre em um vocábulo e cada uma das 
acepções desse vocábulo seria, na verdade, uma lexia diferente. Um vocábulo polissêmico contém, portanto, um conjunto de unidades lexicais. (POLGUÈRE, 2002, p. 40).

Polguère (2002), após refletir sobre os itens polissêmicos, como se dão as suas intersecções de sentidos e apresentar como o fenômeno da polissemia é colocado nos dicionários de língua, apresenta o tratamento do fenômeno da homonímia, nos dicionários. No caso dos itens homonímicos, o linguista apresenta a metodologia já conhecida, de separação de itens, visto se tratar apenas de uma coincidência de formas de palavras:

\footnotetext{
Pode acontecer que dois vocábulos distintos estejam associados aos mesmos significantes mesmo que eles não tenham nenhuma relação de significado; este é um caso de homonímia. Os dicionários frequentemente distinguem lexias homônimas por números sobrescritos, e essa também é a notação adotada na lexicologia explicativa e combinatória. Por exemplo:

ADRESSE $^{1}$ [Ele tem muita habilidade. $]^{2}$

ENDEREÇO $^{2}$ [Você conhece o endereço dele na França?]. (POLGUÈRE, 2002, p. 40, grifos do autor, tradução nossa)
}

Continuando sua reflexão sobre os fenômenos da polissemia e homonímia, Polguère (2002) deixa, então, clara a posição da TST frente aos fenômenos. O linguista procura evidenciar que, no que diz respeito à metodologia de tratamento dos fenômenos em questão, a posição da Teoria Sentido-Texto levará em consideração uma abordagem que privilegia o eixo sincrônico da língua. Isso significa dizer que a tomada de posição da TST para o apontamento da existência de polissemia ou homonímia em um item lexical considerará uma ligação semântica contemporânea. Caso haja um vínculo etimológico, mas esse vínculo não é recuperado no significado do item, sendo perceptível aos usuários de língua, ele será ignorado. (POLGUÈRE, 2002, p. 40).

É possível observar que um tratamento etimológico dos fenômenos é desconsiderado pela teoria, a qual procura fundamentar a sua classificação de um vocábulo como polissêmico ou de diferentes lexias como homonímicas a partir de uma visão sincrônica de língua. Desta forma, observa-se uma reflexão sobre os vocábulos da língua tendo em conta, como citado por Polguère (2002), a "presença ou ausência de ligação semântica”. A presença de uma ligação semântica acontecerá em lexias de um mesmo vocábulo, no caso da polissemia; a ausência de uma ligação semântica se dará 
em lexias distintas que possuem, apenas, uma coincidência de significante, no caso da homonímia.

Por fim, Mel'čuk e Milicévic (2014) comentam, de maneira breve, o caso da polissemia e da homonímia, inseridos no fenômeno da ambiguidade. Os linguistas consideram a homonímia como a identidade de significantes de signos em que os significados desses itens homonímicos não possuem componentes comuns, e a polissemia como identidade de significantes dos signos em que esses tais signos partilham certos componentes dos seus significados.

Como se pode depreender das afirmações realizadas por Mel'čuk e Milicévić (2014) no texto em questão, para a Teoria Sentido-Texto, no fenômeno da homonímia há identidade dos significantes, mas no plano do sentido os significados dos signos homonímicos não possuem componentes comuns importantes. Já no fenômeno da polissemia há também identidade de significantes, mas há mais do que isso, há unidades lexicais cujos significados compartilham componentes bastante importantes.

\subsection{As Funções Lexicais, ferramenta de análise do Modelo Sentido-Texto}

Mel'čuk (2015) apresenta a definição do que é "função lexical”, exibindo sua caracterização formal, bem como uma descrição de sua funcionalidade. O linguista também estabelece uma tipologia das funções e até lista todas as funções standard que o MST estabelece.

Mel'čuk (2015, p. 166) afirma que as funções lexicais têm como principal meta ser uma ferramenta capaz de representar expressões ligadas lexicalmente, que indicam significados determinados.

Com o objetivo de apurar a apresentação do que são as funções lexicais, de maneira formal, Mel’čuk (2015, p. 166) apresenta a notação de uma função lexical (FL). O linguista define a "função lexical" como sendo uma função que realiza a representação de um determinado significado possível em uma língua sendo associado a uma unidade lexical. A palavra-chave, que é a lexia sendo associada à função, é o argumento da função lexical e essa associação entre a palavra-chave e a sua função acarretará no resultado, ou valor, da aplicação da função. A fim de exemplificação, é possível se ter, por exemplo, a unidade lexical "chuva" como a palavra-chave, a Função 
Lexical "Magn" como o sentido "intensificação" sendo associado à determinada lexia. O resultado dessa associação formalmente é $f(L)=\left\{L^{\prime} i\right\}$, e linguisticamente é Magn $($ chuva $)=\{$ chuva forte, chuva intensa, chuva torrencial $\}$. Dito de outra maneira, uma função lexical é a representação de um significado sendo associado (ou "acoplado") a um item lexical, e o resultado dessa associação é uma expressão não livre.

\section{SELEÇÃO E RECOLHA DOS DADOS}

Visto que o presente trabalho tem como objetivo refletir sobre a apresentação dos verbos polissêmicos nos dicionários de língua e quais fenômenos estariam em jogo quanto à descrição das diferentes acepções desse verbo (se a homonímia ou a polissemia), a partir de uma teoria linguística, a Teoria Sentido-Texto, definiu-se como um objeto específico o verbo partir, retirado do Pequeno Dicionário Houaiss de Língua Portuguesa (2015).

O verbo partir, no suporte referido, foi tratado como um verbo polissêmico, com uma entrada apenas e oito acepções:

Quadro 1 - acepções do verbo partir no Pequeno Dicionário Houaiss da Língua Portuguesa

\begin{tabular}{|c|l|}
\hline \multicolumn{2}{|c|}{ Paráfrases do verbo partir } \\
\hline 1 & Dividir(-se) em partes, pedaços. \\
\hline 2 & Fazer(-se) em pedaços; quebrar(-se). \\
\hline 3 & Deixar um local; sair, ir. \\
\hline 4 & Pôr-se a caminho de; dirigir-se. \\
\hline 5 & Ter início, origem, fundamento em. \\
\hline 6 & Dar início a; lançar-se. \\
\hline 7 & Perder a vida; morrer. \\
\hline 8 & Entregar parcela de (algo) a (diversos receptores); distribuir, repartir. \\
\hline
\end{tabular}

Fonte: Adaptado pela autora do Pequeno Dicionário Houaiss da Língua Portuguesa (2015).

A escolha do verbo partir se deu pelo fato de a hipótese levantada ter em consideração os sentidos das acepções do verbo e, desta forma, a existência da possibilidade de poder haver três blocos maiores de sentidos, homônimos entre si. Esses 
blocos foram representados, cada bloco de sentido, pelas letras A, B e C, com as acepções retiradas do dicionário suporte de recolha de dados:

A) (1) Dividir(-se) em partes, pedaços; (2) Fazer(-se) em pedaços; quebrar(-se) e (8) Entregar parcela de (algo) a (diversos receptores); distribuir, repartir.

B) (3) Deixar um local; sair, ir; (4) Pôr-se a caminho de; dirigir-se; (6) Dar início a; lançar-se e (7) Perder a vida; morrer.

C) (5) Ter início, origem, fundamento em.

\section{RESULTADOS}

Como o resultado a ser alcançado pela aplicação de funções lexicais precisa ser o verbo partir, as funções selecionadas foram as funções lexicais standard ${ }^{3}$ sintagmáticas, que modelizam a coocorrência lexical, neste caso o verbo partir e o seu complemento. Também se recorreu, logicamente, às funções lexicais sintagmáticas verbais, cujo resultado é um verbo. Quando não houve possibilidade de formalização com uma função lexical standard, recorreu-se, desta forma, às funções lexicais não standard $^{4}$.

A partir da aplicação das funções lexicais às paráfrases do verbo partir, obtevese o resultado formalizado no quadro abaixo:

Quadro 2 - Formalização das paráfrases do verbo partir em Funções Lexicais

\begin{tabular}{|c|c|c|}
\hline \multirow{3}{*}{1} & Paráfrase & Dividir(-se) em partes, pedaços. \\
\hline & Exemplo & $\begin{array}{l}\text { <partiu o pão e comeu-o com a sopa > <a guerra fez o país p.-se } \\
\text { em dois territórios> }\end{array}$ \\
\hline & $\begin{array}{l}\text { Função } \\
\text { Lexical }\end{array}$ & $\begin{array}{l}\text { \{Divisão, substantivo } \\
\text { Realizar a d. de um objeto/alimento em partes/pedaços = partir } \\
\left.\mathrm{N}_{\mathrm{x}}\right\}\end{array}$ \\
\hline \multirow{3}{*}{2} & Paráfrase & Fazer(-se) em pedaços; quebrar(-se). \\
\hline & Exemplo & $\begin{array}{l}<\text { uma bolada partiu a janela da sala }><0 \text { cálice partiu-se em } \\
\text { centenas de cacos }>\end{array}$ \\
\hline & $\begin{array}{l}\text { Função } \\
\text { Lexical }\end{array}$ & $\begin{array}{l}\text { \{Divisão, substantivo } \\
\text { Realizar a d. de um objeto em partes/pedaços }+ \text { Degrad }^{5}=\text { partir }\end{array}$ \\
\hline
\end{tabular}




\begin{tabular}{|c|c|c|}
\hline & & $\left.\mathrm{N}_{\mathrm{x}}\right\}$ \\
\hline \multirow[b]{3}{*}{3} & Paráfrase & Deixar um local; sair, ir. \\
\hline & Exemplo & $\langle$ partiu cedo de Brasília $>$ \\
\hline & $\begin{array}{l}\text { Função } \\
\text { Lexical }\end{array}$ & $\begin{array}{l}\text { LocabLabreal }^{6}(\text { Brasília })=\text { partiu de } \sim \\
\text { (Função } \text { Loc }_{a b}=\text { de localização, sair para fora de }+ \text { Função } \\
\text { Labreal = de verbo realizacional }) .\end{array}$ \\
\hline \multirow[b]{3}{*}{4} & Paráfrase & Pôr-se a caminho de; dirigir-se. \\
\hline & Exemplo & <o navio partiu para a Europa $>$ \\
\hline & $\begin{array}{l}\text { Função } \\
\text { Lexical }\end{array}$ & $\begin{array}{l}\text { LocinLabreal }(\text { Europa })=\text { partir para ART } ~ \\
\left(\text { Função Loc }{ }_{\text {in }}=\text { de localização, ir para }+ \text { Função Labreal = de }\right. \\
\text { verbo realizacional }) .\end{array}$ \\
\hline \multirow[b]{3}{*}{5} & Paráfrase & Ter início, origem, fundamento em. \\
\hline & Exemplo & $\langle$ p. de uma premissa $\rangle$ \\
\hline & $\begin{array}{l}\text { Função } \\
\text { Lexical }\end{array}$ & $\begin{array}{l}\text { Loc }_{a b} \text { FigurIncepLabreal }{ }^{7} \text { (premissa) }=\text { partir de ART } ~ \\
\text { (Função Loc }{ }_{a b}=\text { de localização, sair para fora de }+ \text { Função Figur } \\
=\text { de sentido metafórico + Função Incep }=\text { de sentido começar }+ \\
\text { Função Labreal = de verbo realizacional). }\end{array}$ \\
\hline \multirow[b]{3}{*}{6} & Paráfrase & Dar início a; lançar-se. \\
\hline & Exemplo & $<$ p. para uma longa viagem $>$ \\
\hline & $\begin{array}{l}\text { Função } \\
\text { Lexical }\end{array}$ & $\begin{array}{l}\text { IncepLocadLabreal }(\text { viagem })=\text { partir para ART } ~ \\
\text { (Função Incep = de sentido começar }+ \text { Função Locab }=\text { de } \\
\text { localização, sair para fora de }+ \text { Função Labreal }=\text { de verbo } \\
\text { realizacional). }\end{array}$ \\
\hline \multirow[b]{3}{*}{7} & Paráfrase & Perder a vida; morrer. \\
\hline & Exemplo & ----- \\
\hline & $\begin{array}{l}\text { Função } \\
\text { Lexical }\end{array}$ & $\begin{array}{l}\text { FigurLocabLabreal }(\text { vida })=\text { partir desta } \sim \\
\text { Função Figur }=\text { de sentido metafórico }+ \text { Função } \operatorname{Loc}_{a b}=\text { de } \\
\text { localização, sair para fora de }+ \text { Função Labreal }=\text { de verbo } \\
\text { realizacional). }\end{array}$ \\
\hline 8 & Paráfrase & $\begin{array}{l}\text { Entregar parcela de (algo) a (diversos receptores); distribuir, } \\
\text { repartir. }\end{array}$ \\
\hline
\end{tabular}




\begin{tabular}{|l|l|l|}
\hline & Exemplo & <partiu os bens entre os filhos $>$ \\
\cline { 2 - 3 } & Função & $\{$ Divisão, substantivo \\
Lexical & Realizar a d. de objetos entre diversos receptores = partir $\}$ \\
\hline
\end{tabular}

Fonte: Elaborado pela autora.

Como é possível observar no quadro acima, a partir das paráfrases e dos exemplos de partir, retirados do Pequeno Dicionário Houaiss da Língua Portuguesa, as Funções Lexicais do Modelo Sentido-Texto mostraram a proximidade das paráfrases em dois grandes grupos, como será discutido na seção seguinte.

\section{DISCUSSÃO}

A hipótese levantada de que o verbo partir poderia ser dividido em homônimos pode ser corroborada a partir da formalização das diferentes acepções em funções lexicais.

As acepções 1- "Dividir(-se) em partes, pedaços"; 2- "Fazer(-se) em pedaços; quebrar(-se)"; e 8- "Entregar parcela de (algo) a (diversos receptores); distribuir, repartir", não foram passíveis de serem formalizadas a partir de funções standard, logo, foram descritas a partir de funções não standard e, no caso da acepção "2", há uma função mista de função standard e não standard. No caso da acepção "2", a formalização deste sentido se dá de maneira próxima das acepções "1" e "8", mas com o acréscimo da função Degrad, que significa tornar-se em um estado pior do que o anterior, o que aprece ser o caso do verbo partir com um significado sinônimo ao de quebrar.

Dado o fato de que foi necessária a formalização dessas três acepções (1, 2 e 8) em funções lexicais não standard, poder-se-ia afirmar que há homonímia neste caso, apesar da proximidade de sentido aparente, já que a descrição dos sentidos não se deu pelas exatas mesmas funções standard. Acontece que, como é possível observar nos resultados deste trabalho, nas três acepções foi possível chegar-se ao resultado partir, tendo em conta um mesmo componente importante, neste caso, o substantivo divisão. Também se poderia evidenciar a proximidade destas três paráfrases aplicando-se, a estas, a função de sinonímia ${ }^{8}$ para o verbo partir, em que o resultado desta aplicação 
apresenta alguns mesmos correlatos (destacados em negrito) para as diferentes acepções:

Quadro 3 - Função Lexical Syn aplicada às acepções "1", "2" e "8" do verbo partir

\begin{tabular}{|c|l|}
\hline $\begin{array}{c}\text { Partir = Dividir(-se) em partes, } \\
\text { pedaços. }\end{array}$ & Syn (partir) = cortar, dividir, separar, seccionar. \\
\hline $\begin{array}{c}\text { Partir = Fazer(-se) em pedaços; } \\
\text { quebrar(-se). }\end{array}$ & $\begin{array}{l}\text { Syn (partir) = quebrar, fender, rasgar, despedaçar, } \\
\text { espatifar, fraturar, lascar, rachar, separar. }\end{array}$ \\
\hline $\begin{array}{c}\text { Partir = Entregar parcela de } \\
\text { (algo) a (diversos receptores); } \\
\text { distribuir, repartir. }\end{array}$ & $\begin{array}{l}\text { Syn (partir) = repartir, dividir, compartilhar, } \\
\text { partilhar, distribuir, subdividir. }\end{array}$ \\
\hline
\end{tabular}

Fonte: Elaborado pela autora.

Quanto ao fato de, primeiramente, ter-se conjecturado a hipótese de poder haver três blocos de sentido para o verbo partir, esta hipótese foi refutada pela formalização das acepções do verbo em funções lexicais. As acepções restantes, “3”, “4”, “5”, “6” e "7" mostraram proximidade, no que diz respeito às funções lexicais pelas quais estas acepções, em questão, foram formalizadas.

A acepção "3- Deixar um local; sair, ir." foi formalizada através da função complexa LocabLabreal, que é a união das funções $\operatorname{Loc}_{a b}$, indicando "movimento para fora de" e Labreal, cujo resultado é um verbo de realização com palavra-chave como objeto indireto. Na acepção “4- Pôr-se a caminho de; dirigir-se.”, há também as funções Loc e Labreal, desta vez com Loc $a$ ad, sugerindo "movimento para": Loc $a d$ Labreal.

$\mathrm{Na}$ acepção "5- Ter início, origem, fundamento em.”, optou-se por uma abordagem baseada em um sentido figurado, o qual teve como ponto de partida as acepções de partir indicando movimento, isto é, as acepções " 3 " e "4". Desta forma, a função complexa LocabFigurIncepLabreal indica o processo metafórico oriundo dos sentidos primeiros (Figur); a função Incep indica a ideia de ter (a premissa) como ponto de partida/início e a função Labreal indica a realização destes sentidos por um verbo que, como já mencionado antes, toma como palavra-chave o seu objeto indireto.

A acepção "6- Dar início a; lançar-se." aproxima-se da função complexa que descreve a acepção "4”, apenas com a diferença de que, no caso da acepção "6” há a ideia de movimento para, com o acréscimo da ideia de início/começo, logo, a função 
que representa a acepção "6" é semelhante à de "4", porém, com a adição da função Incep: IncepLocadLabreal.

Por fim, na acepção "7- Perder a vida; morrer.", optou-se, assim como na acepção "5", por pressupor um processo metafórico para este sentido, a partir dos sentidos primeiros indicando movimento, neste caso mais específico, algo como a "saída de um espaço (abstrato) que seria a vida, para o espaço abstrato/metafórico morte". Assim, a função lexical complexa que modeliza a acepção "7" seria: FigurLocabLabreal.

\section{CONSIDERAÇÕES FINAIS}

A fim de refletir sobre o tratamento da polissemia do verbo partir no Pequeno Dicionário Houaiss da Língua Portuguesa, este trabalho pretendeu modelizar as acepções deste verbo, apresentadas pelo dicionário em questão, nas funções lexicais, ferramenta de análise linguística do Modelo Sentido-Texto.

Tendo em conta o fato de que, como apresentado na introdução deste artigo, e corroborado por Mel'čuk (1995), parece não haver critérios linguísticos plenamente estabelecidos para o tratamento da polissemia e da homonímia nos dicionários de língua, propõe-se, desta forma, a análise das diferentes acepções de verbos polissêmicos a partir das funções lexicais do Modelo Sentido-Texto.

A fim de validar ou refutar a proposta apresentada, neste trabalho, realizou-se uma espécie de protótipo para o tratamento de verbos polissêmicos a partir da abordagem Sentido-Texto, tendo em consideração apenas um verbo retirado do Pequeno Dicionário Houaiss da Língua Portuguesa, o verbo partir.

Tendo como fundamento a modelização das paráfrases do verbo partir, nas Funções Lexicais da Teoria Sentido-Texto, constatou-se que a formalização das acepções deste verbo conforme as funções lexicais de Mel'čuk (2015) evidenciam um afastamento sintático-semântico do verbo partir em dois grupos de acepções, diferentemente de como o verbo é apresentado no seu verbete do Pequeno Dicionário Houaiss da Língua Portuguesa.

No Dicionário Houaiss, há uma abordagem polissêmica do verbo partir, deste modo, há um verbete apenas para as oito acepções apresentadas. A modelização das 
acepções nas funções lexicais, porém, mostrou que o verbo partir poderia ser tratado como dois homônimos que possuem dentro de si acepções polissêmicas:

1) 1Partir. 1. Dividir(-se) em partes, pedaços. 2. Fazer(-se) em pedaços; quebrar(-se). 3. Entregar parcela de (algo) a (diversos receptores); distribuir, repartir.

2) 2Partir. 1. Deixar um local; sair, ir. 2. Pôr-se a caminho de; dirigir-se. 3. Ter início, origem, fundamento em. 4. Dar início a; lançar-se. 5. Perder a vida; morrer.

É importante ressaltar que este trabalho é prévio e pequeno, podendo ser estendido ao tratamento de um número considerável de verbos polissêmicos a partir da abordagem Sentido-Texto, com sua modelização nas funções lexicais, para que haja uma proposta palpável de tratamento linguístico destes verbos, a fim de contribuir para uma apresentação nos dicionários de língua comum baseada em critérios linguísticos, sincrônicos e relacionados ao sentido.

\section{Referências}

HOUAISS. Pequeno Dicionário Houaiss da Língua Portuguesa. São Paulo: Moderna, 2015.

MEL'ČUK, Igor A. MILIĆEVIĆ, Jasmina. Introduction à la linguistique. v. I. Paris: Hermann Éditeurs, 2014.

MEL'ČUK, Igor A. Semantics: From meaning to text. Amsterdam: John Benjamins Publishing Company, 2015.

MEL'ČUK, Igor A. Vers une linguistique Sens-Texte. Collège de France: Chaire Internationale, 1997.

MEL'ČUK, Igor A.; CLAS, André; POLGUÈRE, Alain. Introduction à la lexicologie explicative et combinatoire. Bruxelas: Editions Duculot, 1995.

MILIĆEVIĆ, Jasmina. A short guide to the Meaning-Text Linguistic Theory. Journal of Koralex, v. 8, p. 187-233, 2006.

PERINI, Mário A. Gramática descritiva do português. São Paulo: Ática, 2004.

POLGUÈRE, Alain. Modélisation des liens lexicaux au moyen des fonctions lexicales. Taln, Nancy, p. 37-60, 2002. 


\footnotetext{
${ }^{1}$ A palavra lexia é o termo adotado pela Teoria Sentido-Texto para significar a unidade básica da lexicologia. O que comumente se entende, na linguística, como unidade lexical.

${ }^{2}$ A palavra "adresse" foi mantida no idioma de origem (francês), nesta primeira acepção, visto não ser um sentido encontrado na Língua Portuguesa.

${ }^{3}$ As funções lexicais standard são representadas por formalismos. Explicando de uma maneira mais palpável, cada função (sentido sendo acoplado a outra lexia) recebeu um nome. Esse nome é, geralmente, uma abreviação de quatro ou mais letras de uma palavra do latim, que informa esse sentido sendo veiculado pela função. (MEL'ČUK, 2015, p. 181).

${ }^{4}$ Funções lexicais não standard são as funções não capazes de se aplicarem a um número significativo de palavras chaves. São funções com significados particularizados, criadas conforme a necessidade de sentido da determinada língua em que se realiza a aplicação da determinada função. (Cf. Mel'čuk, 2015, p. 179).

${ }^{5}$ Degrad é a função lexical sintagmática verbal que, acoplada a uma determinada lexia, tem como resultado um verbo que torna algo pior, em relação ao seu estado inicial. Exemplo: Degrad(saúde) = deteriorar.

${ }^{6}$ Loc $_{\text {in }}$ e Loc $_{a b}$ são as funções lexicais de orientação e localização. Respectivamente, apontam localizações como "estar em" e movimentar-se para fora de". Labreal é uma função com resultado verbo realizacional, que veicula o sentido de "cumprir o requerimento da palavra-chave"; exemplo: Labreal (asfalto) $=$ cobrir de.

${ }^{7}$ Figur é a função lexical que tem como resultado um sentido figurado ou metafórico da palavra-chave a qual se ligou. Exemplo: Figur(paixão) = chama. Incep é a função que expressa o sentido de "começar". Exemplo: Incep(filme) $=$ estrear.

8 A função lexical Syn não é uma função sintagmática verbal, mas paradigmática. As funções paradigmáticas servem para demonstrar o paradigma de relações virtuais que uma unidade lexical pode ter com tantas outras. Neste caso, a função Syn foi utilizada como ferramenta para mostrar a proximidade relacional das três acepções em questão. (Cf. Mel’čuk, 2015, p. 177-178).
} 